\title{
Comparison of Physicochemical and Functional Traits of Hanwoo Steer Beef by the Quality Grade
}

\author{
Dong-Gyun Lim, Ju-Su Cha, Cheorun $\mathrm{Jo}^{2}$, Kyung Haeng Lee ${ }^{3}$, Jong-Ju Kim, and Ki-Chang Nam* \\ Department of Animal Science and Technology, Sunchon National University, Suncheon 540-950, Korea \\ ${ }^{1}$ Department of Health Administration and Food Hygiene, Jinju Health College, Jinju 660-757, Korea \\ ${ }^{2}$ Department of Agricultural Biotechnology, Center for Food and Bioconvergence, and Research Institute \\ of Agriculture and Life Science, Seoul National University, Seoul 151-921, Korea \\ ${ }^{3}$ Department of Food and Nutrition, Korea National University of Transportation, Jeungpyeong 368-701, Korea \\ ${ }^{4}$ School of Biotechnology, Yeungnam University, Gyeongsan 712-749, Korea
}

\begin{abstract}
The physicochemical and functional traits for loin muscles of Hanwoo steers were compared by quality grade (QG). A total of 500 Hanwoo steers were slaughtered, their carcasses were categorized into four groups (QG 1++, 1+, 1, and 2), and the longissimus dorsi muscles were analyzed. QG $1++$ group had the highest fat and lowest moisture content $(p<0.05)$. QG $1++$ showed higher $L^{*}$ and $b^{*}$ color values, higher cooking loss, and lower shear force values, compared with the other groups $(p<0.05)$. The flavor, tenderness, juiciness, and preference scores by sensory evaluation were highly ranked for premium QG groups (1++ and 1+). Regarding the micro compounds, QG 1 and QG 2 had greater amounts of inosine monophosphate, and QG 2 had greater amounts of anserine, carnosine, and creatine, than QG $1++(p<0.05)$. QG $1++$ and $1+$ had higher percentages of oleic acid (C18:1) than QG $2(p<0.05)$. Within premium QG 1++ and 1+, the results of the nucleotides, free amino acids, dipeptides, and fatty acids did not show any distinctive differences. Hanwoo beef as determined by the current grading system was not significantly different in terms of functional components; the only significant difference was in intramuscular fat content.
\end{abstract}

Keywords: Hanwoo steers, quality grade, functional components, sensory evaluation

\section{Introduction}

The native beef cattle in Korea are known as Hanwoo; it is a hybrid of Bos taurus $\times$ Bos zebu, which was migrated and settled in the Korean peninsula in BC 4000 (Rhee and Kim 2001). However, commercialized production of Hanwoo as meat-type cattle was started only in 1960 s with the commencing of rapid economic growth in Korea (Jo et al., 2012). Korean consumers prefer beef from Korean native cattle to imported beef because they believe that juiciness and flavor of Hanwoo beef is better than imported beef (Kim et al., 1993). Therefore, Hanwoo beef has been regarded as the most expensive and high quality beef in South Korea. Presently, the prime Hanwoo strip loin received a more than twelve US dollar

\footnotetext{
*Corresponding author: Ki-Chang Nam, Department of Animal Science and Technology, Sunchon National University, Suncheon 540-742, Korea. Tel: +82-61-750-3231, Fax: +82-61750-3230, E-mail: kichang@scnu.kr
}

premium per kilogram compared to that for an average quality (Hwang et al., 2010).

Consumers are using quality grades as a reference when purchasing beef products. Under the Korean meat market circumstance, carcass quality is largely determined by marbling score (Park et al., 2002), and consequently breeders and producers have forced on the improvement of marbling. Marbling is a prime theme in Korean beef industry, as consumer judge meat quality on the basis of the degree of marbling, and they are willing to pay premium for highly marbled product (Moon et al., 2003; Neely et al., 1998; Savell et al., 1989). Better quality grades have a heavier carcass weight with a higher marbling score, redder meat color and whiter fat color (Moon et al., 2003).

Korean government introduced beef carcass grading specifications in 1992 to be evaluated by beef quality. The quality grade $(\mathrm{QG})$ has five possible values $(1++, 1+, 1,2$, 3 ), and the yield grade (YG) has three possible values (A, B, C) for the evaluation of beef quality in Korean beef carcass grade system (KAPE, 2013). The quality of beef 
is primarily based upon marbling score and additionally determined by lean color, fat color, texture and maturity of the exposed longissimus dorsi (LD) muscle at the 13th rib interface (Moon et al., 2006; NLCF, 1998). Quality grade $1++$ is the highest or most desirable grade and grade 3 is the lowest degree of quality (Kim and Lee, 2003). Typically, $54 \%$ of slaughtered Hanwoo cattle are at or above quality grade 1 compared with $10.7 \%$ for Holstein bulls and $0.6 \%$ for Holstein cows. Of Hanwoo cattle slaughtered in $2008,7.5 \%$ were grade $1++, 18.1 \%$ grade $1+$, and $31.7 \%$ grade 1 . Of 220,355 Hanwoo steers carcasses, $12.3 \%$ were grade $1++, 30.3 \%$ were grade $1+$, and $33.1 \%$ were grade 1 . Of 263,189 Hanwoo cow carcasses, $6.4 \%$ were grade $1++, 18.1 \%$ were grade $1+$, and $31.7 \%$ were grade 1 (KAPE, 2013).

Korean consumers preferred the high quality graded beef, but there is little information concerning both meat quality and functional components of Hanwoo beef according to Korean carcass quality grade system. The objective of this study was to investigate the effect of quality grade on the physicochemical, functional, and sensory traits of M. longissimus dorsi of Hanwoo steers.

\section{Materials and Methods}

\section{Animals and sample preparation}

A total of 500 Hanwoo steer (27-30 mon old) were randomly selected from a local cattle farm by Nong-Hyup (Anseong, Korea), slaughtered without electrical stimulation, and then immediately cooled at $0^{\circ} \mathrm{C}$ for $24 \mathrm{~h}$ in a chilling room. The carcass weight was ranged 213 to 477 $\mathrm{kg}$ (average $409 \mathrm{~kg}$ ). The cold carcasses were graded by an official meat grader at $24 \mathrm{~h}$ postmortem with the loin surface ribbed between the 13th rib and the 1st lumbar vertebrae according to the Korean carcass grading procedure (NLCF, 1998). The Longissimus dorsi (LD) muscles at the 14th to 18th vertebrate were removed and transferred to laboratories. After ageing during $7 \mathrm{~d}$ at $4^{\circ} \mathrm{C}$, the subcutaneous and intermuscular fat and visible connective tissue of LD muscles were trimmed and used to analyze meat composition, quality, and functional parameters of Hanwoo beef.

\section{Proximate composition}

The proximate composition of each LD muscles was obtained with a slightly modified method of AOAC (2000). Briefly, moisture content was measured by drying $3 \mathrm{~g}$ of samples place in aluminum dishes at $104^{\circ} \mathrm{C}$ for $15 \mathrm{~h}$. The crude protein contents were measured by the Kjeldahl me- thod (VAPO45, Gerhardt Ltd., Idar-Oberstein, Germany). The crude fat contents were extracted according to the method described by Folch et al. (1957). The crude ash contents were measured by burning in a furnace at $600^{\circ} \mathrm{C}$ overnight.

\section{Instrument color values}

The surface color value were measured by the CIE L*, $a^{*}$ and $b^{*}$ system using a Minolta colorimeter (Model CR-410, Minolta Co. Ltd., Japan). The colorimeter was calibrated against a white reference tile plate $\left(\mathrm{L}^{*}=89.2\right.$, $a^{*}=0.921, b^{*}=0.783$ ), and the diameter size of aperture was $4 \mathrm{~cm}$. The color $\mathrm{L}^{*}$ (lightness), $\mathrm{a}^{*}$ (redness), and $\mathrm{b}^{*}$ (yellowness) values were obtained after $30 \mathrm{~min}$ blooming at room temperature. The average value of five random measurements taken from different locations was used for the statistical analysis.

\section{Physicochemical quality parameters}

The $\mathrm{pH}$ value of each filtrate was determined with a $\mathrm{pH}$ meter (Orion 2 Star, Thermo scientific, USA). Water holding capacity (WHC) was determined by the centrifugation. Briefly, $5 \mathrm{~g}$ of minced meat sample was placed into a centrifugation tube with a filter paper (No. 4, Whatman International Ltd., England), and centrifuged at 3,000×g for $10 \mathrm{~min}$. WHC was calculated as the remaining moisture in the meat sample on the basis of the moisture content of the original meat sample. The drip loss was measured as the percentage weight loss of a standardized $(3 \times 3$ $\times 3 \mathrm{~cm}$ ) meat sample placed in a sealed petri-dish at $4^{\circ} \mathrm{C}$ during the storage of $2 \mathrm{~d}$. The cooking loss was determined as the percentage weight loss of a standardized $(3 \times$ $3 \times 3 \mathrm{~cm}$ ) meat sample after cooking in an electric grill with double pans (Nova EMG-533, 1,400 W, Evergreen enterprise, Korea) for $90 \mathrm{~s}$ until the internal temperature of the meat sample reached $72^{\circ} \mathrm{C}$.

\section{Shear force measurement}

The samples were prepared a cubic form $(30 \times 30 \times 20$ $\mathrm{mm}$ ), heated until internal temperature of the samples reached $72 \pm 2^{\circ} \mathrm{C}$, and then cooled for $30 \mathrm{~min}$ at room temperature. Each sample was cut perpendicular to the longitudinal orientation of the muscle fiber with a WarnerBratzler shear attachment on a texture analyzer (TA-XT2, Stable Micro System Ltd., U.K.). The maximum shear force value $(\mathrm{kg})$ was recorded for each sample. Test and pre-test speeds were set at $2.0 \mathrm{~mm} / \mathrm{s}$. Post-test speeds were set at $5.0 \mathrm{~mm} / \mathrm{s}$. 


\section{Sensory evaluations}

For the sensory evaluation, meat samples were cooked in an electric grill with double pans (Nova EMG-533, $1,400 \mathrm{~W}$, Evergreen, Korea) to an internal temperature of $75^{\circ} \mathrm{C}$. The meat samples $(2 \times 4 \times 1.5 \mathrm{~cm})$ were placed into randomly coded white dishes and served with drinking water. Ten trained panelists recorded their preferences using a 9-point hedonic scales (1=profoundly dislike, 5=like moderately, 9=profoundly like) after training the panelists using the Hanwoo beef with quality grade $1^{+}$as a reference. The sensory parameters tested were color, odor, tenderness, juiciness, and overall acceptance for cooked Hanwoo beef.

\section{Nucleotide-related compounds}

The meat samples $(5 \mathrm{~g})$ were mixed with $25 \mathrm{~mL}$ of 0.7 $\mathrm{M}$ perchloric acid and centrifuged at $1,130 \mathrm{~g}$ for $1 \mathrm{~min}$ to extract nucleic acids. The extracted nucleic acids were then centrifuged at 2,090 $\mathrm{g}$ for $15 \mathrm{~min}$ and filtered through a Whatman No.4 filter paper (Whatman Inc., USA). The supernatant was then adjusted to $\mathrm{pH} 7$ with $5 \mathrm{~N}$ $\mathrm{KOH}$. The $\mathrm{pH}$-adjusted supernatant was placed in a volumetric flask and made up to a volume of $100 \mathrm{~mL}$ with 0.7 $\mathrm{M}$ perchloric acid ( $\mathrm{pH} \mathrm{7.0)}$. After $30 \mathrm{~min}$ of cooling, it was centrifuged at $1,130 \mathrm{~g}\left(0^{\circ} \mathrm{C}\right)$ and the supernatant was filtered through a $0.2 \mu \mathrm{m}$ PVDF syringe filter (Whatman, England). The filtrate (5 mL) was analyzed using HPLC (ACME 9000, Younglin Instruments Inc, Korea). With regard to the analytical conditions for HPLC, a WatersAtlantis dC18 RP column $(4.6 \times 250 \mathrm{~mm}, 5 \mu \mathrm{m}$ particles, Waters Co., USA) was utilized, with a mobile phase of $0.1 \mathrm{M}$ triethylamine in $0.15 \mathrm{M}$ acetonitrile ( $\mathrm{pH} 7.0)$. The flow rate of the mobile phase was $1.0 \mathrm{~mL} / \mathrm{min}$ and the injection volume was $10 \mu \mathrm{L}$. The column temperature was maintained at $35^{\circ} \mathrm{C}$ and the detection was monitored at a wavelength of $260 \mathrm{~nm}$. The peaks of the individual nucleotides were identified using the retention times for standards: hypoxanthine, inosine, inosine-5'-phosphate (IMP), adenosine-5'-phosphate (AMP) (Sigma, USA), and the concentration was calculated using the area for each peak.

\section{Free amino acids}

The soluble amino acid composition was determined by using a modification of the method described by Hughes et al. (2002). The meat was defatted by solvent extraction, according to the method of Lee et al. (1996). Defatted meat sample $(5 \mathrm{~g})$ was mixed with $20 \mathrm{~mL}$ of $2 \%$ TCA solution and homogenized at 13,500 rpm/min for $1 \mathrm{~min}$. The homogenate was centrifuged at $17,000 \mathrm{~g}$ for $15 \mathrm{~min}$ and filtered through $0.45 \mu \mathrm{m}$ membrane filter. The filtrate was derivatized by the method of Waters AccQ-Tag ${ }^{\mathrm{TM}}$ (1993, Millipore Co-Operative, USA) and $5 \mathrm{~mL}$ was injected into a RP-HPLC (AccQ $\cdot$ Tag $^{\mathrm{TM}}$ column, $3.9 \times 150 \mathrm{~mm}$, Waters). The column temperature was $37^{\circ} \mathrm{C}$ and a fluorescent detector (Waters ${ }^{\mathrm{TM}} 2475$, Millipore, USA) was used with $250 \mathrm{~nm}$ and $395 \mathrm{~nm}$ of excitation and emission wavelength, respectively. Accuracy and repeatability of this analysis is ensured by the inclusion of a control sample of known amino acid composition with the samples prior to hydrolysis.

\section{Dipeptides}

Dipeptides contents of the meat samples were determined by the method of Mora et al. (2007). Minced meat sample $(2.5 \mathrm{~g})$ was homogenized with $7.5 \mathrm{~mL}$ of $0.01 \mathrm{~N}$ $\mathrm{HCl}$ at $13,500 \mathrm{rpm} / \mathrm{min}$ for $1 \mathrm{~min}$. The homogenate was centrifuged at $17,000 \mathrm{~g}$ for $15 \mathrm{~min}$, and the supernatant was mixed with $750 \mathrm{~mL}$ acetonitrile. After stored at $4^{\circ} \mathrm{C}$ for $20 \mathrm{~min}$ and then centrifuged at $10,000 \mathrm{rpm}$ for $10 \mathrm{~min}$, it was injected into a HPLC with a Waters 1525 pump and a Waters 717 plus auto sampler (Millipore Co-Operative, USA). Atlantis HILIC silica column $(4.6 \times 150 \mathrm{~mm}$, $3 \mu \mathrm{m}$, Waters) was used. A diode array detector (Waters 2487, Millipore Co-Operative, USA) was used at $214 \mathrm{~nm}$ for determining creatine, carnosine, and anserine, and at $236 \mathrm{~nm}$ for creatinine. Mobile A phase was $0.65 \mathrm{mM}$ ammonium acetate in water/acetonitrile $(25: 75, \mathrm{v} / \mathrm{v}, \mathrm{pH} 5.5)$ and $\mathrm{B}$ phase was $0.55 \mathrm{mM}$ ammonium acetate in water/ acetonitrile (70:30, v/v, $\mathrm{pH} 5.5)$. B phase was supplied at $1.2 \mathrm{~mL} / \mathrm{min}$ for $16 \mathrm{~min}$ with linear gradient $(0-100 \%)$. Standards (creatine, anserine, carnosine, and creatinine) were used from Sigma (USA).

\section{Fatty acids and cholesterol}

Lipids for fatty acid analysis were extracted from meat samples according to the method of Folch et al. (1957). Meat sample (5 g) were homogenized with $30 \mathrm{~mL}$ Folch solution (chloroform:methanol=2:1) and the homogenate was filtered through a filter paper. After adding 0.88\% $\mathrm{KOH}$ solution, the filtrate was thoroughly mixed. After phase separation, the upper layer was removed and the remaining organic layer was dried under nitrogen flow $(99.99 \%)$. The dried lipid was dissolved with an aliquot of hexane (at $100 \mathrm{mg}$ lipid/mL hexane) and used for the fatty acid and cholesterol analysis.

One $\mathrm{mL} \mathrm{BF}_{3}$-methanol (Sigma, USA) was added to 100 $\mathrm{mL}$ of lipid extract and incubated in a $90^{\circ} \mathrm{C}$ for $1 \mathrm{~h}$. After cooling, $2 \mathrm{~mL}$ hexane and $5 \mathrm{~mL}$ distilled water were added, 
mixed thoroughly, and left overnight for phase separation. The top (hexane) layer containing methylated fatty acids was analyzed using a GC (HP 7890, Agilent Technologies, USA). A capillary column (HP-88, $60 \mathrm{~m} \times 0.25$ $\mathrm{mm} \times 0.25 \mathrm{~mm}$, Agilent Technologies, USA) was used. A ramped oven temperature condition $\left(180^{\circ} \mathrm{C}\right.$ for $1 \mathrm{~min}$, increased to $230^{\circ} \mathrm{C}$ at $2.5^{\circ} \mathrm{C} / \mathrm{min}$, then held at $230^{\circ} \mathrm{C}$ for $12 \mathrm{~min}$ ) was used. Temperatures of both the inlet and detector were $280^{\circ} \mathrm{C}$. Helium was the carrier gas at linear flow of $1 \mathrm{~mL} / \mathrm{min}$. FID detector air, H2, and make-up gas (He) flows were 350,35 , and $41 \mathrm{~mL} / \mathrm{min}$, respectively. Heptadecanoic acid (C17:0) was used as an internal standard (catalogue number H3500, Sigma-Aldrich Inc., USA). The fatty acid methyl esters (FAME) in the total lipids were identified by comparison of the retention times with those of a standard FAME mixture (SuplecoTM 37 Component FAME Mix, Catalogue number 47885-UP, Lot number, LB-85684. Sigma-Aldrich Inc., USA). Fatty acids were expressed as a percentage of total fatty acids identified, saturated fatty acid (SFA), mono-unsaturated fatty acid (MUFA) and polyunsaturated fatty acid (PUFA). PUFA/SFA and n- $6 / n-3$ ratios were calculated.

For analysis of cholesterol, $10 \mathrm{~mL}$ of saponification reagent $(33 \% \mathrm{KOH}(\mathrm{w} / \mathrm{v}) /$ ethanol, 6:94) were added to lipid extract. The sample was homogenized and then incubated at $50^{\circ} \mathrm{C}$ for $1 \mathrm{~h}$. After cooling, $5 \mathrm{~mL}$ of distilled water and $5 \mathrm{~mL}$ of hexane were added. The contents were mixed thoroughly and the hexane layer containing unsaponifiable matters was dried under nitrogen gas $(99.99 \%)$. The dried sample was then mixed with $200 \mathrm{~mL}$ of pyridine and $100 \mathrm{~mL}$ of Sylon BFT (99\% BSTFA+1\% TMCS) and derivatized at $50^{\circ} \mathrm{C}$ for $1 \mathrm{~h}$. Analysis was performed with a HP 6890 GC equipped with an on-column capillary injector and a FID detector. A capillary column (HP$5,30 \mathrm{~m} \times 0.25 \mathrm{~mm} \times 0.25 \mathrm{~mm}$ ) and a ramped oven temperature were used (increased to $260^{\circ} \mathrm{C}$ from $180^{\circ} \mathrm{C}$ at $8^{\circ} \mathrm{C} / \mathrm{min}$, then increased to $280^{\circ} \mathrm{C}$ at $2^{\circ} \mathrm{C} / \mathrm{min}$ ). The amounts were calculated using an internal standard, 5a-cholestane. The content of cholesterol was expressed as $\mathrm{mg} /$
$100 \mathrm{~g}$ of meat.

\section{Statistical methods}

An analysis of variance were performed on all the variables measured using the General Linear Model (GLM) procedure of the SAS statistical package (SAS, 1999). Data given in the tables are means and standard error of the means. Differences in the mean values were tested by Student-Newman-Keul method. A probability level (P) of 0.05 was used to determine differences among the treatment means $(p<0.05)$. The mean values and the standard errors of the means (SEM) were reported.

\section{Results and Discussion}

\section{Carcass characteristics, nutritive composition, and meat color}

The carcass weight of quality grade (QG) 2 was significantly lower than the other group, and the back fat depth of quality grade $1++$ were higher than the others (Table 1). Proximate composition and cholesterol of LD muscles from Hanwoo by quality grade are also presented in Table 1. Moisture and crude protein contents significantly decreased with increasing quality grade from grade 2 to grade $1++(p<0.05)$. However, crude fat content for LD muscles was $24.25 \%$ in QG $1++$, followed by QG $1+(17.44 \%)$, QG 1 (14.05\%), and QG 2 (7.09\%), which is understandable because the most predominating parameter to determine the QG is intramuscular fat content (marbling) in Korean beef carcass grade system (KAPE, 2013). QG 2 contained the highest moisture $(70.92 \%)$ and crude protein $(20.18 \%)$ and crude ash $(1.83 \%)$ when compared with the other three groups, while QG 1++ muscles contained the lowest $(p<0.05)$.

This result agreed to the previous studies (Cho et al., 2010; Lee et al., 2010) that reported that the protein and moisture contents were higher in QG 2, and the fat contents were higher in QG 1++ compared to the other grades. This is also confirmed an earlier report by Kim and

Table 1. Carcass characteristics and nutritive composition of loins from Hanwoo with different quality grade

\begin{tabular}{|c|c|c|c|c|c|}
\hline & $\overline{1++}$ & $\overline{1+}$ & $\overline{1}$ & $\overline{2}$ & SEM $^{\top}$ \\
\hline Carcass weight (kg) & $421.3^{\mathrm{a}}$ & $420.2^{\mathrm{a}}$ & $412.1^{\mathrm{a}}$ & $400.8^{b}$ & 3.5 \\
\hline Back fat depth (mm) & $14.6^{\mathrm{a}}$ & $13.3^{\mathrm{b}}$ & $12.9^{\mathrm{b}}$ & $12.7^{\mathrm{b}}$ & 0.1 \\
\hline Moisture (\%) & $55.79^{d}$ & $62.06^{\mathrm{c}}$ & $64.84^{\mathrm{b}}$ & $70.92^{\mathrm{a}}$ & 0.31 \\
\hline Crude protein $(\%)$ & $18.98^{\mathrm{b}}$ & $19.19^{\mathrm{b}}$ & $19.26^{\mathrm{b}}$ & $20.18^{\mathrm{a}}$ & 0.11 \\
\hline Crude fat $(\%)$ & $24.25^{\mathrm{a}}$ & $17.44^{\mathrm{b}}$ & $14.05^{\mathrm{c}}$ & $7.09^{\mathrm{d}}$ & 0.32 \\
\hline Crude ash (\%) & $0.96^{\mathrm{c}}$ & $1.03^{b c}$ & $1.17^{\mathrm{ab}}$ & $1.83^{\mathrm{a}}$ & 0.01 \\
\hline Cholesterol (mg\%) & 61.78 & 59.79 & 58.08 & 59.80 & 0.27 \\
\hline
\end{tabular}

${ }^{1}$ Standard error of the means $(\mathrm{n}=500)$.

${ }^{\mathrm{a}-\mathrm{d}}$ Means with different letters within the same row differ significantly $(p<0.05)$. 
Lee (2003) who the QG 1 meat had significantly more crude fat content and less moisture than other grades. Moon et al. (2006) reported that the crude fat content was closely related to marbling score as evaluated by the meat graders. Previous studies have also reported an inverse relationship between intramuscular fat and moisture content in bovine muscle (Park et al., 2000; Savell et al., 1986). Cholesterol for LD muscles did not differ among the four quality grade groups. In the present study, cholesterol LD muscles among quality grade ranged from 60.33 to $61.67 \mathrm{mg} / 100 \mathrm{~g}$. Bures et al. (2006) noted similar findings among the quality grade which ranged from 59 to $68 \mathrm{mg} / 100 \mathrm{~g}$, which is similar to our results. A slight tendency towards higher cholesterol contents in beef having increased IMF contents was found by Bures et al. (2006), but not in the present study.

Comparisons of meat color of LD muscles among quality grade are shown in Table 2. CIE L* (lightness) and $b^{*}$ (yellow) value significantly increased with increasing quality grade from QG 2 to QG $1++(\mathrm{p}<0.05)$. QG $1++$ showed a higher CIE L* (lightness) and $b^{*}$ (yellow) value when compared to the other grades. Similar findings were obtained by Kim and Lee (2003) who observed high quality grade LD muscles had higher $\mathrm{b}^{*}$ value than low quality grade. Lee et al. (2010) showed that $\mathrm{L}^{*}$ values were significantly higher in QG 1++ compared to the other grades. Also, distinctive differences observed between $1++$ and $1+$ QG groups in moisture and crude fat contents.

\section{Physicochemical traits and sensory evaluation}

Quality grade significantly $(p<0.05)$ affected the drip loss and cook loss of LD muscles although it gave similar values among the four groups (Table 3 ). The $\mathrm{pH}$, WHC and drip loss were not significantly different among the groups. The $\mathrm{pH}$ values were similar in all quality groups (all mean values were between 5.52 and 5.57). Previous study (Kim and Lee, 2003) showed that $\mathrm{pH}$ values among the quality grade groups from Hanwoo LD muscles were not statistically different. Water holding capacity (WHC) was expressed as a ratio of the meat film area to the total expressible juice area; therefore large values indicate a higher actual WHC (Kim and Lee, 2003). The WHC increased with increase of the quality grade, but the WHC among the four grade groups did not differ. This is in agreement with the previous research (Kim and Lee, 2003; Lee et al., 2010), which reported there were no significant differences in WHC among the groups. Drip loss was also significantly different by quality grade, and the similar finding was obtained by Kim and Lee (2003).

Cooking loss was significantly different by quality grade. The cooking loss of QG 1++ was the worst, and the values were decreased as the quality grade was lower. This result can be attributed to the loss of fat during the cooking process. However, the results disagree with previous studies (Kim and Lee, 2003; Park et al., 2000), which cooking loss among steaks samples from the three grades did not differ. Ozawa et al. (2000) reported that cooking loss of Japanese black steer meat was significantly lower for samples with the highest marbling score. This might be due to the difference resulted from the method for cooking loss. The shear force values of $1++$ were lower than the others, and the values of quality QG 2 were the greatest. The higher intramuscular fat in $1++$ can be a factor for the lower shear force values. Cho et al. (2010) also evaluated WBSF values of LD muscles were significantly lower for QG 1++ compared with QG 2. Marbling often

Table 2. CIE color values of loins from Hanwoo with different quality grade

\begin{tabular}{cccccc}
\hline \hline & $1++$ & $1+$ & 1 & 2 & SEM $^{\mathrm{l}}$ \\
\hline $\mathrm{L}^{*}$ & $40.70^{\mathrm{a}}$ & $39.84^{\mathrm{b}}$ & $38.52^{\mathrm{c}}$ & $37.46^{\mathrm{d}}$ & 0.15 \\
$\mathrm{a}^{*}$ & 22.06 & 21.87 & 21.46 & 21.63 & 0.13 \\
$\mathrm{~b}^{*}$ & $13.94^{\mathrm{a}}$ & $13.63^{\mathrm{ab}}$ & $13.05^{\mathrm{bc}}$ & $12.66^{\mathrm{c}}$ & 0.10 \\
\hline
\end{tabular}

${ }^{1}$ Standard error of the means $(\mathrm{n}=500)$.

${ }^{\mathrm{a}-\mathrm{d}}$ Means with different letters within the same row differ significantly $(p<0.05)$.

Table 3. Physicochemical traits of loins from Hanwoo with different quality grade

\begin{tabular}{cccccc}
\hline \hline & $1++$ & $1+$ & 1 & 2 & SEM $^{1}$ \\
\hline $\mathrm{pH}$ & 5.52 & 5.52 & 5.54 & 5.57 & 0.01 \\
WHC (\%) & 71.14 & 70.76 & 69.82 & 69.97 & 0.30 \\
Drip loss (\%) & $17.92^{\mathrm{b}}$ & $18.00^{\mathrm{b}}$ & $18.60^{\mathrm{ab}}$ & $19.22^{\mathrm{a}}$ & 0.16 \\
Cooking loss (\%) & $20.69^{\mathrm{a}}$ & $19.34^{\mathrm{b}}$ & $18.02^{\mathrm{c}}$ & $17.04^{\mathrm{d}}$ & 0.14 \\
Shear force (kg) & $48.91^{\mathrm{c}}$ & $53.93^{\mathrm{b}}$ & $56.11^{\mathrm{ab}}$ & $58.37^{\mathrm{a}}$ & 0.49 \\
\hline
\end{tabular}

${ }^{1}$ Standard error of the means $(n=500)$.

${ }^{\mathrm{a}-\mathrm{d}}$ Means with different letters within the same row differ significantly $(p<0.05)$. 
Table 4. Sensory evaluation of loins from Hanwoo with different quality grade

\begin{tabular}{cccccc}
\hline \hline & $1++$ & $1+$ & 1 & 2 & SEM $^{2}$ \\
\hline Color $^{\mathrm{l}}$ & 5.25 & 5.45 & 5.14 & 5.04 & 0.06 \\
Flavor & $6.07^{\mathrm{a}}$ & $5.90^{\mathrm{a}}$ & $5.13^{\mathrm{b}}$ & $4.10^{\mathrm{c}}$ & 0.10 \\
Tenderness & $5.92^{\mathrm{a}}$ & $5.86^{\mathrm{a}}$ & $4.67^{\mathrm{b}}$ & $3.98^{\mathrm{c}}$ & 0.09 \\
Juiciness & $5.99^{\mathrm{a}}$ & $5.84^{\mathrm{a}}$ & $4.89^{\mathrm{b}}$ & $4.06^{\mathrm{c}}$ & 0.08 \\
Preference & $6.15^{\mathrm{a}}$ & $5.70^{\mathrm{b}}$ & $4.61^{\mathrm{c}}$ & $3.93^{\mathrm{d}}$ & 0.08 \\
\hline
\end{tabular}

${ }^{1} 1$ : extremely bad 9: extremely good.

${ }^{2}$ Standard error of the means $(n=500)$.

${ }^{\mathrm{a}-\mathrm{d}}$ Means with different letters within the same column differ significantly $(p<0.05)$.

Table 5. Nucleotide-related compounds of loins from Hanwoo with different quality grade (unit: mg\%)

\begin{tabular}{cccccc}
\hline \hline & $1++$ & $1+$ & 1 & 2 & SEM $^{\mathrm{l}}$ \\
\hline IMP & $100.22^{\mathrm{b}}$ & $110.80^{\mathrm{b}}$ & $126.35^{\mathrm{a}}$ & $129.83^{\mathrm{a}}$ & 3.24 \\
Inosine & 29.77 & 26.66 & 26.58 & 25.55 & 0.52 \\
AMP & 6.64 & 6.57 & 7.06 & 6.93 & 0.10 \\
Hypoxanthine & 20.98 & 19.93 & 21.51 & 20.29 & 0.41 \\
\hline
\end{tabular}

${ }^{1}$ Standard error of the means $(n=500)$.

${ }^{\mathrm{a}, \mathrm{b}}$ Means with different letters within the same row differ significantly $(p<0.05)$.

has been regarded as a contributing factor to beef palatability and is used as the most important factor in evaluating the beef quality (Tatum et al., 1982).

Sensory evaluation of loins from Hanwoo by quality grade is presented in Table 4. Color did not differ significantly among the four groups. Quality QG $1++$ and $1+$ had significantly higher flavor, tenderness, and juiciness scores than the others $(p<0.05)$. QG $1++$ LD muscles contained the highest flavor (6.07), tenderness (5.92), and juiciness (5.99) compared with the other three groups. Flavor, tenderness, and juiciness significantly increased with increasing quality grade $(p<0.05)$. Therefore, the overall preference was clearly ranked by the quality grade.

These results are consisted with those of the previous research (Kim and Lee, 2003) that the QG 1 steaks had higher tenderness and juiciness score than QG 3 steaks. These findings also suggested that meat quality grade for Hanwoo affect the sensory characteristics of meat, mainly juiciness and tenderness. Many authors have proven tenderness and juiciness are positively related to intramuscular fat content in most studies (Fiems et al., 2000; Renand et al., 2001; Wheeler et al., 1996). Park et al. (2000) reported beef loin with high intramuscular fat had high scores in juiciness and tenderness. A decrease in marbling level had resulted in a reduction in juiciness, tenderness, and flavor intensity scores (Savell et al., 1989). The overall acceptance is the sum of all sensory parameters. Cho et al. (2010) found that Korean consumers decided their overall acceptability of Hanwoo beef in following proportions: weights of tenderness $55 \%$, juiciness $18 \%$, and flavor-likeness $27 \%$. Therefore the higher overall acceptabi- lity scores of beef with increasing quality grade might be associated to the synergistic effect of higher tenderness and juiciness scores of those quality grade groups (Table 4). In addition, higher IMF content (marbling) played a vital role in determining overall acceptance scores (Okumura et al., 2007). As a result of the physicochemical traits and sensory evaluation, a clear difference of Hanwoo LD muscles was observed by the quality grade. Distinctive differences were also observed between $1++$ and $1+$ QG in preference score.

\section{Nucleotide-related compounds, amino acids, and dipeptides}

Nucleotide-related compounds result from the decomposition of adenosine triphosphate (ATP) (Flores et al., 1999). ATP is the major compound in muscle before slaughter, whereas muscle after slaughter contains large amounts of inosine monophosphate (IMP) and small amounts of ATP, AMP, and ADP (Lee and Lee, 2001). ATP becomes AMP by dephosphorylation and is then converted to IMP, which provides good taste to meat. And IMP changes to inosine, and then to hypoxanthine, which has a bitter taste (Tikk et al., 2006). There was only significant difference in IMP among the nucleotide-related compounds (Table 5). QG 1++ and 1+ LD muscles contained higher IMP compared with the other two groups $(p<$ 0.05). AMP, inosine, and hypoxanthine were not significantly different. Cho et al. (2008) investigated that 1++ QG Hanwoo steer beef had higher IMP in eye of round and top round. It is well documented that nucleotiderelated compounds, free amino acids, and peptides are 
Table 6. Free amino acids of loins from Hanwoo with different quality grade (unit: $\mathrm{mg} \%$ )

\begin{tabular}{cccccc}
\hline \hline & $1++$ & $1+$ & 1 & 2 & SEM $^{1}$ \\
\hline Ala & $48.43^{\mathrm{b}}$ & $48.69^{\mathrm{b}}$ & $44.39^{\mathrm{b}}$ & $56.46^{\mathrm{a}}$ & 0.96 \\
Asp & 2.10 & 2.23 & 2.17 & 2.50 & 0.10 \\
Cys & 6.64 & 6.63 & 6.32 & 5.03 & 0.23 \\
Glu & 13.38 & 13.83 & 10.41 & 14.01 & 0.45 \\
Gly & $12.35^{\mathrm{ab}}$ & $12.28^{\mathrm{ab}}$ & $10.42^{\mathrm{b}}$ & $13.52^{\mathrm{a}}$ & 0.29 \\
His & $95.12^{\mathrm{b}}$ & $101.91^{\mathrm{b}}$ & $102.39^{\mathrm{b}}$ & $125.00^{\mathrm{a}}$ & 2.43 \\
Ile & $6.71^{\mathrm{a}}$ & $6.62^{\mathrm{a}}$ & $4.82^{\mathrm{b}}$ & $6.72^{\mathrm{a}}$ & 0.22 \\
Leu & $11.48^{\mathrm{a}}$ & $11.48^{\mathrm{a}}$ & $8.61^{\mathrm{b}}$ & $11.74^{\mathrm{a}}$ & 0.36 \\
Lys & 13.12 & 13.70 & 10.94 & 13.62 & 0.35 \\
Met & $5.29^{\mathrm{a}}$ & $5.31^{\mathrm{a}}$ & $3.75^{\mathrm{b}}$ & $5.27^{\mathrm{a}}$ & 0.19 \\
Phe & $7.12^{\mathrm{a}}$ & $7.10^{\mathrm{a}}$ & $5.26^{\mathrm{b}}$ & $7.07^{\mathrm{a}}$ & 0.23 \\
Pro & $5.59^{\mathrm{b}}$ & $5.70^{\mathrm{b}}$ & $5.28^{\mathrm{b}}$ & $6.63^{\mathrm{a}}$ & 0.13 \\
Ser & $14.32^{\mathrm{ab}}$ & $14.7^{\mathrm{a}}$ & $11.88^{\mathrm{b}}$ & $15.78^{\mathrm{a}}$ & 0.41 \\
Thr & $33.97^{\mathrm{b}}$ & $34.86^{\mathrm{b}}$ & $32.81^{\mathrm{b}}$ & $44.30^{\mathrm{a}}$ & 0.94 \\
Tyr & $7.57^{\mathrm{a}}$ & $7.32^{\mathrm{a}}$ & $5.77^{\mathrm{b}}$ & $8.18^{\mathrm{a}}$ & 0.22 \\
Val & $9.44^{\mathrm{a}}$ & $9.44^{\mathrm{a}}$ & $7.07^{\mathrm{b}}$ & $9.76^{\mathrm{a}}$ & 0.31 \\
\hline
\end{tabular}

${ }^{1}$ Standard error of the means $(n=500)$.

${ }^{\mathrm{a}, \mathrm{b}}$ Means with different letters within the same row differ significantly $(p<0.05)$.

responsible for improving the taste, flavour and aroma of meat during storage (Jo et al., 2012; Rikimaru and Takahashi, 2010). However, IMP is generally considered as the major nucleotide in muscle that imparts flavor to the meat (Jo et al., 2012).

Free amino acids of loins from Hanwoo by quality grade are given in Table 6. Tseng et al. (2005) classified free amino acid in food to umami (aspartic acid, glutamic acid), sweet (serine, glycine, threonine, alanine), bitter (valine, methionine, isoleucine, leucine, phenylalanine, histidine, arginine), and other taste (glutamine, tyrosine, lysine and proline). QG 1 had significantly lower glycine, isoleucine, leucine, methionine, phenylalanine, serine, tyrosine, and valine than others $(p<0.05)$. QG 2 had significantly more alanine, histidine, proline and threonine than QG $1(p<$ $0.05)$. The results showed that the high amino acid in QG 2 corresponded well with a high crude protein contents. However, any characteristic differences of free amino acids by quality grade were not found in the present study.

Dipeptides of loins from Hanwoo by quality grade are given in Table 7. QG 2 had more anserine, carnosine, and creatine content than $1++$ group $(p<0.05)$. Dipeptides including carnosine, anserine and creatine are considered as bioactive components in meat because they provide antioxidant or energy-providing including prevention and treatment of a disease (Peiretti et al., 2012). Peiretti et al. (2012) recently found $1,680-1,720 \mathrm{mg}$ of carnosine and 160-270 mg of anserine in $100 \mathrm{~g}$ of freeze-dried beef. Additionally, they reported a reduction in carnosine content in cooked beef which was attributed to the high water solubility of carnosine and related compounds. The results of this study concerning the nucleotide, amino acid and dipeptide have showed that no distinctive differences found between QG 1++ and 1+.

\section{Fatty acids composition}

Fatty acid compositions of LD muscles from Hanwoo by quality grade are presented in Table 8 . The major fatty acids were oleic (C18:1), palmitic (C16:0), stearic (C18: 0 ), palmitoleic (C16:1), linoleic (C18:2) and myristic (C14:0) acid. These fatty acids accounted for over $88 \%$ of the total fatty acids in the intramuscular fat (IMF). The difference by quality grade was shown in some fatty acids. QG 2 had significantly more C15:0, C17:0, C17:1, C20:3, $\mathrm{C} 20: 4$ and $\mathrm{C} 24: 1$ than others $(p<0.05)$. Oleic acid $(\mathrm{C} 18: 1)$ makes up the largest proportion of the monounsaturated fatty acid (MUFA). QG 1++ and 1+ had higher percentage of oleic acid (C18:1) and unsaturated fatty acid (UFA) contents than QG $2(p<0.05)$. Similar findings were obtained by Lee et al. (2010) who found out UFA were higher in loin of QG $1++$.

There was no significant difference by quality grade on total saturated fatty acids (SFA), the ratio of unsaturated fatty acids to saturated fatty acids (UFA/SFA), and the ratio of n- $6 / n-3$ unsaturated fatty acids related with a risk of coronary heart disease (Enser, 2001). Therefore, WHO (2003) recommends reducing the intake of SFA and increasing the intake of $n-3$ fatty acids. Meats from ruminant animals had a more favorable $n-6 / n-3$ ratio due to the less C18:2 high C18:3 than pork (Wood et al., 2004). Hanwoo beef had significantly higher $\mathrm{n} 6 / \mathrm{n} 3$ ratio than Angus which had high contents of n-3 PUFA (C18:3n3, C20:5n3, C22:

Table 7. Dipeptides of loins from Hanwoo with different quality grade (unit: mg\%)

\begin{tabular}{cccccc}
\hline \hline & $1++$ & $1+$ & 1 & 2 & SEM $^{\mathrm{t}}$ \\
\hline Anserine & $107.11^{\mathrm{b}}$ & $114.90^{\mathrm{ab}}$ & $120.56^{\mathrm{ab}}$ & $137.81^{\mathrm{a}}$ & 3.44 \\
Carnosine & $697.19^{\mathrm{c}}$ & $778.39^{\mathrm{ab}}$ & $762.39^{\mathrm{b}}$ & $817.60^{\mathrm{a}}$ & 8.97 \\
Creatine & $1444.27^{\mathrm{c}}$ & $1564.80 \mathrm{~b}$ & $1633.70^{\mathrm{a}}$ & $1663.40^{\mathrm{a}}$ & 8.76 \\
Creatinine & 18.06 & 19.49 & 19.13 & 17.39 & 0.51 \\
\hline
\end{tabular}

${ }^{1}$ Standard error of the means $(n=500)$.

${ }^{\mathrm{a}-\mathrm{c}}$ Means with different letters within the same row differ significantly $(p<0.05)$. 
Table 8. Fatty acid composition of loins from Hanwoo with different quality grade (unit: \%)

\begin{tabular}{|c|c|c|c|c|c|}
\hline & $1+1++$ & $1+$ & 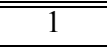 & 2 & $\overline{\text { SEM }}^{1}$ \\
\hline C10:0 & 0.04 & 0.04 & 0.04 & 0.04 & 0.00 \\
\hline C12:0 & $0.07^{\mathrm{b}}$ & $0.08^{\mathrm{ab}}$ & $0.08^{\mathrm{a}}$ & $0.09^{\mathrm{a}}$ & 0.00 \\
\hline C14:0 & 2.38 & 2.52 & 2.54 & 2.61 & 0.03 \\
\hline C14:1 & $0.74^{\mathrm{a}}$ & $0.81^{\mathrm{a}}$ & $0.76^{\mathrm{a}}$ & $0.68^{b}$ & 0.02 \\
\hline C15:0 & $0.2^{\mathrm{b}}$ & $0.21^{\mathrm{b}}$ & $0.23^{\mathrm{ab}}$ & $0.26^{\mathrm{a}}$ & 0.01 \\
\hline C16:0 & 22.69 & 22.87 & 23.07 & 22.80 & 0.12 \\
\hline C16:1 & 4.01 & 4.03 & 3.63 & 3.66 & 0.08 \\
\hline C17:0 & $0.55^{\mathrm{b}}$ & $0.58^{\mathrm{b}}$ & $0.59^{\mathrm{b}}$ & $0.68^{\mathrm{a}}$ & 0.01 \\
\hline C17:1 & 0.65 & 0.66 & 0.64 & 0.66 & 0.01 \\
\hline C18:0 & $10.05^{\mathrm{b}}$ & $9.92^{\mathrm{b}}$ & $10.64^{\mathrm{b}}$ & $10.99^{\mathrm{a}}$ & 0.13 \\
\hline C18:1 & $44.59^{\mathrm{a}}$ & $44.58^{\mathrm{a}}$ & $43.39^{\mathrm{ab}}$ & $42.77^{\mathrm{b}}$ & 0.20 \\
\hline C18:1, 11t & 2.09 & 2.25 & 2.10 & 1.95 & 0.05 \\
\hline C18:2 & 2.85 & 2.86 & 3.00 & 3.12 & 0.07 \\
\hline C20:0 & 0.05 & 0.05 & 0.05 & 0.05 & 0.00 \\
\hline C18:3 & 0.12 & 0.11 & 0.10 & 0.10 & 0.00 \\
\hline CLA, 9c11t & 0.35 & 0.34 & 0.33 & 0.33 & 0.01 \\
\hline C20:1 & $0.36^{\mathrm{a}}$ & $0.32^{\mathrm{ab}}$ & $0.32^{\mathrm{ab}}$ & $0.28^{\mathrm{b}}$ & 0.01 \\
\hline CLA $10 \mathrm{t} 12 \mathrm{c}$ & 0.02 & 0.03 & 0.02 & 0.02 & 0.00 \\
\hline $\mathrm{C} 20: 2$ & $0.04^{\mathrm{b}}$ & $0.11^{\mathrm{ab}}$ & $0.19^{\mathrm{a}}$ & $0.17^{\mathrm{a}}$ & 0.02 \\
\hline $\mathrm{C} 20: 3$ & $0.30^{\mathrm{b}}$ & $0.27^{\mathrm{b}}$ & $0.31^{\mathrm{b}}$ & $0.37^{\mathrm{a}}$ & 0.01 \\
\hline C20:4 & $0.53^{b c}$ & $0.50^{\mathrm{c}}$ & $0.66^{\mathrm{ab}}$ & $0.74^{\mathrm{a}}$ & 0.02 \\
\hline $\mathrm{C} 24: 1$ & $0.16^{\mathrm{b}}$ & $0.14^{\mathrm{b}}$ & $0.17^{\mathrm{b}}$ & $0.22^{\mathrm{a}}$ & 0.00 \\
\hline SFA & 36.01 & 36.27 & 37.24 & 37.39 & 0.20 \\
\hline UFA & $56.8^{\mathrm{a}}$ & $56.99^{\mathrm{a}}$ & $55.62^{\mathrm{ab}}$ & $55.2^{\mathrm{b}}$ & 0.22 \\
\hline PUFA & 3.41 & 3.49 & 3.88 & 4.32 & 0.09 \\
\hline UFA/SFA & 1.59 & 1.58 & 1.51 & 1.49 & 0.01 \\
\hline$n-6 / n 3$ & 8.42 & 9.43 & 9.55 & 8.67 & 0.16 \\
\hline
\end{tabular}

${ }^{1}$ Standard error of the means $(n=500)$.

${ }^{\mathrm{a}-\mathrm{c}}$ Means with different letters within the same row differ significantly $(p<0.05)$.

5n3) and lower contents of n-6 PUFA (C18:2n6, C18:3n6 and C22:4n6) (Cho et al., 2005).

Korean consumers tend to purchase beef with high quality grade, since marbling is one of the key factors determining carcass grade. Within quality grades of Hanwoo beef, the present study did not show any negative points in the fatty acids compositions of premium QG beef. The unsaturated fatty acids including oleic acid were higher in QG 1++ than the others. A few functional fatty acids, conjugated linoleic acids such as CLA 9c11t and CLA 10t12c, were not significantly different among different QG groups, notwithstanding remarkable differences in fat content and the sensory preference. In conclusion, Hanwoo beef determined by current grading system did not show any distinctive difference of the compositions of functional components but did in only intramuscular fat content. However, further research will be given to develop a better beef quality grade system in the aspects of meat quality, functional, and sensory traits, because consumers are getting interested in the health benefits of what they eat.

\section{Acknowledgements}

This study was jointly supported by the Ministry of Agriculture, Food and Rural Affairs, republic of Korea (2012) (No. 311016-3), and Radiation Technology R\&D program (2013M2A2A6043308) through the National Research Foundation of Korea funded by the Ministry of Science, ICT \& Future Planning.

\section{References}

1. AOAC (2000) Official methods of analysis. $17^{\text {th }}$ ed, Association of Official Analytical Chemists, Washington, DC.

2. Bures, D., Barton, L., Zahradkova, R., Teslik, V., and Krejcova, M. (2006) Chemical composition, sensory characteristics, and fatty acid profile of muscle from Aberdeen Angus, Charolais, Simmental, and Hereford bulls. Czech J. Anim. Sci. 51, 279-284.

3. Cho, S. H., Kim, J., Park, B. Y., Seong, P. N., Kang, G. H., Kim, J. H., Jung, S. G., Im, S. K., and Kim, D. H. (2010). Assessment of meat quality properties and development of a palatability prediction model for Korean Hanwoo steer beef. Meat Sci. 86, 236-242. 
4. Cho, S. H., Park, B. Y., Kim, J. H., Hwang, I. H., Kim, J. H., and Lee, J. M. (2005) Fatty acid profiles and sensory properties of Longissimus dorsi, Triceps brachii, and Semimembranosus muscles from Korean Hanwoo and Australian Angus beef. Asian Australas. J. Anim. Sci. 18, 1786-1793.

5. Cho, S. H., Seong, P. N., Kim, J. H., Park, B. Y., Baek, B. H., Lee, Y. J., In, T. C., Lee, J. M., Kim, D. H., and Ahn, J. N. (2008). Calorie, cholesterol, collagen, free amino acid, nucleotide-related compounds and fatty acid composition of Hanwoo steer beef with $1++$ quality grade. Korean J. Food Sci. An. 28, 333-343.

6. Enser, M. (2001). The role of fats in human nutrition. In: Oils and fats. Rossell, B. (ed) Leatherhead Publishing, Surrey, UK, pp. 77-122.

7. Fiems, L. O., De Campeneere, S., De Smet, D., Van de Voorde, G., Vanacker, J. M., and Boucque, C. V. (2000). Relationship between fat depots in carcasses of beef bulls and effect on meat colour and tenderness. Meat Sci. 56, 41-47.

8. Flores, M., Armero, E., Aristoy, M. C., and Toldra, F. (1999) Sensory characteristics of cooked pork loin as affected by nucleotide content post-mortem meat quality. Meat Sci. 51, 53-59.

9. Folch, J., Lee, M., and Sloane-Stanley, G. H. (1957). A simple method for the isolation and purification of total lipids from animal tissues. J. Biol. Chem. 226, 497-507.

10. Hughes, M. C., Kerryb, J. P., Arendtb, E. K., Kenneallyc, P. M., McSweeneya, P. L. H., and O'Neilla, E. E. (2002) Characterization of proteolysis during the ripening of semi-dry fermented sausages. Meat Sci. 62, 205-216.

11. Hwang, Y. H., Kim, G. D., Jeong, J. Y., Hur, S. J., and Joo, S. T. (2010). The relationship between muscle fiber characteristics and meat quality traits of highly marbled Hanwoo (Korean native cattle) steers. Meat Sci. 86, 456-461.

12. Jo, C., Cho, S. H., Chang, J., and Nam, K. C. (2012) Keys to production and processing of Hanwoo beef: A perspective of tradition and science. Animal Frontiers 2, 32-38.

13. KAFE (2013) Report of business for animal products grading. Korea Institute for Animal Products Quality Evaluation, Korea.

14. Kim, C. J. and Lee, E. S. (2003). Effects of quality grade on the chemical, physical and sensory characteristics of Hanwoo (Korean native cattle) beef. Meat Sci. 63, 397-405.

15. Kim, D. H., Kim, Y. K., Chung, Y. H., Yoo, Y. M., and Park, B. Y. (1993). A study on the consumer's attitude to beef: 1 . Consumer's purchasing pattern and preference. RDA J. Agric. Sci. 35, 598-601.

16. Lee, C. M., Trevino, B., and Chaiyawat, M. (1996). A simple and rapid solvent extraction method for determining total lipids in fish tissue. J. Assoc. Offic. Anal. Chem. 79, 487-492.

17. Lee, K. H. and Lee, Y. S. (2001) Changes of nucleotides and their related compounds in cultured and wild red sea bream and flounder muscle. Korean J. Food Soc. Cookery Sci. 17, 517-522.

18. Lee, Y. J., Kim, C. J., Park, B. Y., Seong, P. N., Kim, J. H., Kang, G. H., Kim, D. H., and Cho, S. H. (2010). Korean J. Food Sci. An. 30, 997-1006.
19. Moon, S. S., Hwang, I. H., Jin, S. K., Lee, J. G., Joo, S. T., and Park, G. B. (2003). Carcass traits determining quality and yield grades of Hanwoo steer. Asian Australas. J. Anim. Sci. 16, 1049-1054.

20. Moon, S. S., Yang, H. S., Park, G. B., and Joo, S. T. (2006). The relationship of physiological maturity and marbling judged according to Korean grading system to meat quality traits of Hanwoo beef females. Meat Sci. 74, 516-521.

21. Mora, L., Sentandreu, M. A., and Toldrá, F. (2007) Hydrophilic chromatographic determination of carnosine, anserine, balenine, creatine, and creatinine. J. Agric. Food Chem. 55, 46644669.

22. Neely, T. R., Lorenzen, C. L., Miller, R. K., Tatum, J. D., Wise, J. W., Taylor, J. F., Buyck, M. J., Reagan, J. O., and Savell, J. W. (1998). Beef customer satisfaction: role of cut, USDA quality grade, and city on in-home consumer ratings. J. Anim. Sci. 76, 1027-1032.

23. NLCF (1998) Korean carcass grading standard. National Livestock Cooperatives Federation, Seoul, Korea.

24. Okumura, T., Saito, K., Nade, T., Misumi, S., Masuda, Y., Sakuma, H., Nakayama, S., Fujita, K., and Kawamura, T. (2007) Effects of intramuscular fat on the sensory characteristics of M. longissimus dorsi in Japanese black steers as judged by a trained analytical panel. Asian Australas. J. Anim. Sci. 20, 577-581

25. Ozawa, S., Mitsuhashi, T., Mitsumoto, M., Matsumoto, S., Itoh, N., and Itagaki, K. (2000). The characteristics of muscle fiber types of longissimus thoracis muscle and their influences on the quantity and quality of meat from Japanese Black steers. Meat Sci. 54, 65-70.

26. Park, B. Y., Cho, S. H., Yoo, Y. M., Kim, J. H., Lee, J. M., and Joung, S. K. (2000). Effect of intramuscular fat contents on the physicochemical properties of beef longissimus dorsi from Hanwoo. Korean J. Anim. Sci. Technol. 42, 189-194.

27. Park, G. B., Moon, S. S., Ko, Y. D., Ha, J. K., Chang, H. H., and Joo, S. T. (2002). Influence of slaughter weight and sex on yield and quality grades of Hanwoo (Korean native cattle) carcasses. J. Anim. Sci. 80, 129-136.

28. Peiretti, P. G., Medana, C., Visentin, S., Bello, F. D., and Meineri, G. (2012). Effect of cooking method on carnosine and its homologues, pentosidine and thiobarbituric acid-reactive substance contents in beef and turkey meat. Food Chem. 132, 80-85.

29. Renand, G., Picard, B., Touraille, C., Berge, P., and Lepetit, J. (2001). Relationship between muscle characteristics and meat quality traits of young Charolais bulls. Meat Sci. 59, 4960.

30. Rhee, M. S. and Kim, B. C. (2001). Effect of low voltage electrical stimulation and temperature conditioning on postmortem changes in glycolysis and calpains activities of Korean native cattle (Hanwoo). Meat Sci. 58, 231-237.

31. Rikimaru, K. and Takahashi, H. (2010) Evaluation of the meat from Hinai-jidori chickens and broilers: Analysis of general biochemical components, free amino acids, inosine 5'-monophosphate, and fatty acids. J. Appl. Poult. Res. 19: 327-333.

32. SAS (1999) SAS/STAT Software for PC. Release 6.11, SAS 
Institute, Cary, NC, USA.

33. Savell, J. W., Cross, H. R., and Smith, G. C. (1986). Percentage ether extractable fat and moisture content of beef longissimus muscle as related to USDA marbling score. J. Food Sci. 51, 838-845.

34. Savell, J. W., Cross, H. R., Francis, J. J., Wise, J. W., Hale, D. S., Wilkes, D. L., and Smith, G. C. (1989). National consumer retail beef study: Interaction of trim level, price and grade on consumer acceptance of beef steaks and roasts. J. Food Qual. 12, 251-260.

35. Tatum, J. D., Smith, G. C., and Carpenter, Z. L. (1982). Interrelationships between marbling, subcutaneous fat thickness, and cooked beef palatability. J. Anim. Sci. 34, 777-784.

36. Tikk, M., Tikk, K., Torgen, M. A., Meinert, L., Aaslyng, M. D., Karlsson, A. H., and Anderson, H. J. (2006) Development of inosine monophosphate and its degradation products during aging of pork of different qualities in relation to basic taste and retronasal flavor perception of the meat. J. Agric. Food
Chem. 54, 7769-7777.

37. Tseng, Y. H., Lee, R. C., Li, J. L., and Mau, J. L. (2005) Nonvolatile flavour components of Ganoderma tsugae. Food Chem. 90, 409-415.

38. Wheeler, T. L., Cundiff, L. V., Koch, R. M., and Crouse, J. D. (1996). Characterization of biological types of cattle (cycle IV): carcass traits and longissimus palatability. J. Anim. Sci. 74, 1023-1035.

39. WHO (2003) Diet, nutrition and the prevention of chronic diseases. Report of a joint WHO/FAO expert consultation. Geneva: WHO technical report series, p. 916.

40. Wood, J. D., Nute, G. R., Richardson, R. I., Whittington, F. M., Southwood, O., Plastow, G., Mansbridge, R., da Costa, N., and Chang, K. C. (2004). Effects of breed, diet and muscle on fat deposition and eating quality in pigs. Meat Sci. 67, 651-667.

(Received 2013.12.16/Revised 2014.4.2/Accepted 2014.4.14) 